OPEN ACCESS

Edited by:

David M. Labiner,

University of Arizona College of

Medicine, USA

Reviewed by:

Dieter Schmidt,

Epilepsy Research Group Berlin,

Germany

Detlev Boison,

Legacy Health, USA

${ }^{*}$ Correspondence:

Andrei Surguchov

asurguchov@kumc.edu

Specialty section: This article was submitted to

Epilepsy,

a section of the journa

Frontiers in Neurology

Received: 23 July 2016 Accepted: 04 January 2017

Published: 18 January 2017

Citation:

Surguchov A, Surgucheva I, Sharma $M$, Sharma $R$ and Singh $V$ (2017) Pore-Forming Proteins as

Mediators of Novel Epigenetic

Mechanism of Epilepsy.

Front. Neurol. 8:3.

doi: 10.3389/fneur.2017.00003

\section{Pore-Forming Proteins as Mediators of Novel Epigenetic Mechanism of Epilepsy}

\author{
Andrei Surguchov ${ }^{1 *}$, Irina Surgucheva', Mukut Sharma ${ }^{2,3}$, Ram Sharma ${ }^{2}$ and Vikas Singh ${ }^{1,2}$ \\ ${ }^{1}$ Department of Neurology, Kansas University Medical Center, Kansas City, KS, USA, ${ }^{2}$ Kansas City Veterans Administration \\ Medical Center, Kansas City, MO, USA, ${ }^{3}$ Midwest Biomedical Research Foundation, Kansas City, MO, USA
}

Epilepsy is a disorder of the brain characterized by an enduring predisposition to generate epileptic seizures. In the last two decades, numerous gene defects underlying different forms of epilepsy have been identified with most of these genes encoding ion channel proteins. Despite these developments, the etiology of majority of non-familial epilepsies has no known associated genetic mutations and cannot be explained by defects in identified ion channels alone. We hypothesize that de novo formation of ion channels by naturally unfolded proteins (NUPs) increases neuronal excitability. Altered ionic homeostasis may initiate/contribute to cellular cascades related to epileptogenesis in susceptible individuals. Here, we consider two small proteins, namely, $\alpha$-synuclein and stefin B, as prototypical candidates to illustrate the underlying mechanism(s). Previous work points to an association between epilepsy and $\alpha$-synuclein or stefin B, but the mechanism(s) underlying such association remains elusive. We review the evidence to link the structure-function of these proteins with disease processes. Epigenetic mechanisms unrelated to altered DNA sequence(s) that may affect epileptogenesis include transcriptional or posttranscriptional regulation. Such epigenetic mechanisms or their combination(s) enhance the levels of these proteins and as a result the ability to form annular structures, which upon incorporation into membrane form novel ion channels and disturb intracellular ion homeostasis. Alternative epigenetic mechanisms may change amyloidogenic proteins by posttranslational modifications, thereby increasing their propensity to form channels. Further research elucidating the details about the formation of ion channels through these mechanisms and their role in epileptogenesis may define new molecular targets and guide the development of new drug targets.

Keywords: epilepsy, ion channels, $\alpha$-synuclein, stefin B, epigenetic mechanisms, posttranslational modifications, microRNA, Parkinson's disease

\section{INTRODUCTION}

Epilepsy is a group of neurological diseases characterized by recurrent episodes of convulsive seizures, sensory disturbances, abnormal behavior, loss of consciousness, or a combination of these signs and/or symptoms. As defined by International League Against Epilepsy, epilepsy is a disorder of the brain characterized by an enduring predisposition to generate epileptic seizures that are more than $24 \mathrm{~h}$ apart (1). Although epilepsy can manifest itself in a number of different ways, it shares the 
common feature of persistently increased neuronal excitability and spontaneous seizure generation.

Epilepsy is a widespread disease, being the fourth most common neurological disorder in the United States after migraine, stroke, and Alzheimer's disease. Approximately 150,000 new cases are diagnosed in the United States annually, and 1 in 26 individuals will develop epilepsy at some point in their lifetime. The total indirect and direct cost of epilepsy in the United States is estimated to be $\$ 15.5$ billion per year (2).

Despite recent advancements in epilepsy treatment, currently available interventions and antiepileptic drugs (AEDs) are not effective in over $30 \%$ of patients (3). The current state of known mechanisms of epilepsy and the range of available treatments suggest additional pathways and mechanisms responsible for currently intractable cases of epilepsy. This underscores the importance of more research needed to better understand the underlying disease mechanisms and identify novel drug targets or treatment strategies (4). We present available evidence for the potential role of epigenetic mechanisms and certain naturally unfolded proteins (NUPs) that may create pores in cell membranes and contribute to dysregulated ion flows that characterize electric discharges.

\section{MECHANISM OF IDIOPATHIC EPILEPSY IS NOT CLEAR}

Genetic mutations play an important etiological role in the development of epilepsy in hereditary cases of this disease (5-10). However, the mechanism of seizures in a significant proportion of patients remains unexplained. Such individuals include those with traumatic brain injury (TBI), intracranial infection, brain tumor, stroke, vascular disturbances, intoxication, or chemical imbalance. Additionally, there exists a large cohort of patients who may not be accounted for under these categories of associated conditions. Development of such idiopathic epilepsies represents a spectrum of changes from initial injury to established disease state. These changes include molecules to pathways and single cell structure to cellular network organization.

Epileptogenesis summarizes interactive changes in cellular processes that culminate in the development of a epilepsy. Epileptogenesis spans over a period without overt manifestation of symptoms, while subcellular structural and functional alterations may occur. These changes include neuronal death, axonal growth and sprouting, altered inter neuron connections, and reorganization of neuronal networks. Temporal connections among these changes or their relationships with the onset of neuronal hyperexcitability and spontaneous seizures are not well understood. Cellular events during epileptogenesis may include epigenetic mechanisms that modify processing of RNA and/or proteins leading to non-familial epilepsy.

\section{DEFECTS IN IONIC CHANNELS CAUSE SEIZURES}

Common to all types of epilepsy is an uncontrolled electrical discharge from neurons. Therefore, ion channels are recognized as the key target in understanding the mechanism and treatment of epilepsy. Ion channels constitute a unique group of cellular proteins, which are highly significant in excitable cells due to their role in generation and regulation of electrical discharges. Ion channels are formed by multimeric arrangements of ionophoric membrane proteins. These proteins organize to provide a passageway (channel) across the membrane connecting its outer and inner sides. Such channels permit a controlled flow of ions across the two sides of membrane regulating the resting potential, action potential, and other electrical properties of the membrane while modulating cellular responses to the microenvironment. Ion channels also contribute to regulated cellular responses to changes in cellular environment and maintain ion homeostasis.

Ion channels constitute the most favored class of targets for currently available treatments. Most AEDs have been designed to target ion channels and transporters and one that affects synaptic vesicle protein Sv2a with a goal to favor inhibition of over excitation and thereby decrease or prevent seizure activity/ frequency (11-13). These include AEDs targeting voltage-gated sodium channels, voltage-gated calcium channels, voltage-gated potassium channels, the GABA system and receptor agonists, glutamate receptor antagonists, and other inhibitory neurotransmitters. Additionally, currently used AEDs reduce neuronal hyperexcitability and thereby suppress epileptic seizures.

Despite these developments, available AEDs have had only limited success. Current drugs, more than 20, are employed solely to suppress seizures. Seizures can be effectively controlled in $~ 70 \%$ of patients, whereas $30 \%$ remain refractory to drug treatment pointing to alternative mechanisms and significant unmet need for effective intervention. Second, the existing armamentarium does not affect the comorbidities of epilepsy and does not prevent the development and progression of epileptogenesis (14-16). By and large, the entire process of epileptogenesis offers a number of targets but remains underappreciated.

Altered ion channel function is used as a leading reason of the etiology of seizures and epilepsy. However, lack of explanation for disease manifestation in the absence of gene mutations represents gap in our understanding of the mechanism(s) of the disease. Thus, altered ion homeostasis while ion channels are not genetically altered remains an unanswered question. With these problems in view, a better understanding of the events of epileptogenesis may lead to prevention of seizures, early diagnoses, and treatment of epilepsy in those patients who do not benefit from current treatments.

\section{EPIGENETIC MECHANISMS CONTROL GENE FUNCTION WITHOUT DNA MUTATION}

Recent developments show that DNA may undergo multiple enzymatic modifications, which are used in epigenetic regulation of gene expression. Epigenetics is the study of alterations in the function of genes that do not involve changes in the DNA sequence itself, but rather its expression. Epigenetic mechanisms involve the transfer of information arising from short-lived 
cellular signals and changes in neuronal activity into lasting effects on gene expression.

Rapid exponential advances in high-throughput DNA sequencing technologies convincingly demonstrate that a considerable number of epileptic patients do not carry mutations in genes encoding ion channels or related genes, thereby implying alternative mechanisms involved. Therefore, it is important to learn what other molecular mechanisms, not associated with alterations in genome sequence, may contribute to the development of epilepsy.

Importantly, from the viewpoint of treatment, epigenetic changes are potentially reversible and therefore may form the basis for the future development of efficient therapies. Major epigenetic mechanisms include DNA methylation, histone modification, and microRNA-driven posttranscriptional regulation of gene expression. Methylation-dependent gene silencing is currently one of the most thoroughly investigated mechanisms for regulation of gene expression (17-21).

\section{EPILEPSY SUCH AS TBI-INDUCED EPILEPSY MAY BE CAUSED BY EPIGENETIC MECHANISMS}

Epigenetics may explain the process of epileptogenesis such as posttraumatic epilepsy (PTE) in TBI. Although the study of epigenetic mechanisms of PTE is an emerging area of investigation, the results of several studies point to the importance of this approach in understanding the consequences of TBI in general and PTE in particular. For example, Gao et al. (22) demonstrated that TBI may cause epigenetic changes in an animal model of TBI. Specifically, alterations in hippocampal CA3 histone $\mathrm{H} 3$ acetylation and methylation occur hours to days following injury. In another study, global hypomethylation was observed after TBI in a subpopulation of reactive microglia/ macrophages (23). An important, but not completely understood clue to understanding of TBI-induced epigenetic alterations is the finding that TBI causes relocation of DNA-methyltransferase 1 -enzyme catalyzing sequence-specific DNA methylation (24). However, a detailed mechanism underlying this translocation and its connection with methylation pattern changes require further studies.

\section{IDIOPATHIC FORMS OF EPILEPSY MAY BE ASSOCIATED WITH THE FORMATION OF NEW ION CHANNELS BY NUPS}

Posttraumatic epilepsy is just one example of the development of epilepsy without an underlying, inherited mutation(s). Below we discuss another example based on the formation de novo ion channels from amyloidogenic proteins, which may be responsible for non-familial cases of epilepsy.

In addition to the heterogeneous family of authentic ion channels, a group of naturally unfolded intrinsically unstructured proteins can form novel ion channels as a result of their conformational transitions. This group consists of the so-called
NUPs, which can aggregate to form oligomers and amyloid structures. These proteins may accumulate as large amyloid deposits and inclusions in Alzheimer's disease (amyloid beta, A $\beta$ ) (25-27), Parkinson's disease ( $\alpha$-synuclein), and prion disease (prion protein, PrP) (28-33). Alternatively, NUPs can form annular protofibrils that can act as ion channels increasing membrane conductance $(34,35)$ (Figure 1).

The formation of ion channels from NUPs is a well-known phenomenon (35-37). However, the role of such channels generated under de novo conditions has not been investigated to explore the development of epilepsy.

Ion channel-like membrane pores may be ion-specific or nonselective with regard to ions. Amyloidogenic proteins generally produce rather large pores (3-10 $\mathrm{nm}$ in diameter), which are relatively non-selective for ion traffic $(38,39)$. However, well-defined sizes and morphologies have been found for some amyloid pores such as those generated from $\alpha$-synuclein (34).

\section{$\alpha$-SYNUCLEIN AND STEFIN B ARE CANDIDATE PORE-FORMING PROTEINS}

We present below several observations showing that proteins forming annular protofibrils and thus affecting membrane conductance are associated with epilepsy. We will discuss here two NUPs that can form membrane pores or channels, namely, $\alpha$-synuclein and stefin $\mathrm{B}$. These proteins have several similar properties, which may determine their ability to form new ionic channels and therefore a role in epilepsy:

(a) These are small size proteins that can readily interact with membranes to form oligomers, annular structures, and amyloid fibrils (40, 41, 42).

(b) Their properties are regulated by posttranslational modifications $(43,44)$.

(c) A lack of cysteine prevents formation of disulfide bonds in both proteins (45-47).

(d) Expression of $\alpha$-synuclein and stefin B is regulated by epigenetic mechanisms, such as methylation/demethylation of regulatory regions in their genes $(48,49)$.

(e) Both proteins lack export signal sequences; however, they are detectable in both intracellular and extracellular spaces $(45,47)$.

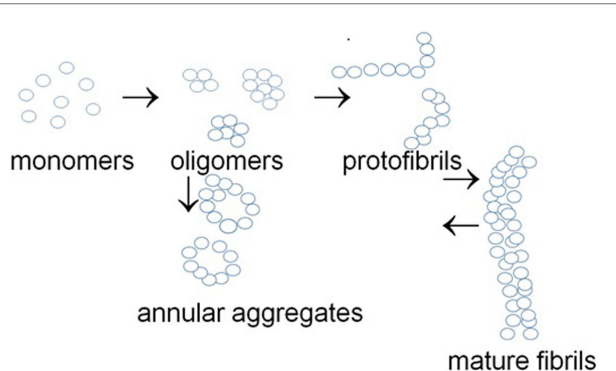

FIGURE 1 | Examples of various aggregated states of naturally unfolded proteins 
Conversely, there is a difference between $\alpha$-synuclein and stefin $B$ with regard to their association with epilepsy. Several missense mutations in stefin B are linked to epilepsy (50), whereas rare missense mutations in $\alpha$-synuclein gene (Figure $2 \mathbf{B}$ ) are associated with Parkinson's disease (51-53).

No data about association of mutations in $\alpha$-synuclein gene with epilepsy are currently available.

Mechanisms that link Parkinson's disease with epilepsy require further exploration but are beyond the scope of this review.

\section{$\alpha-S y n u c l e i n$}

$\alpha$-Synuclein is a major structural component of intracellular protein inclusions or Lewy bodies that constitute a pathological hallmark of Parkinson's disease. Furthermore, $\alpha$-synuclein is implicated in multiple system atrophy, dementia with Lewy bodies, and other diseases $(37,60)$. However, the exact mechanism of $\alpha$-synuclein toxicity and its role in healthy cells and in diseases remain elusive. While a direct link between mutations in $\alpha$-synuclein and epilepsy has not been described so far, several findings point to an association of $\alpha$-synuclein with this disease. These include the following:

(a) Patients with $\alpha$-synuclein gene multiplication have seizures. Although a rare event, multiplication of $\alpha$-synuclein gene resulting in its abundance in the central and peripheral nervous system generates different disease phenotypes, including seizures and myoclonus (61).

(b) $\alpha$-Synuclein concentration is elevated in the CSF and serum of epileptic patients (62), as well as in a mouse

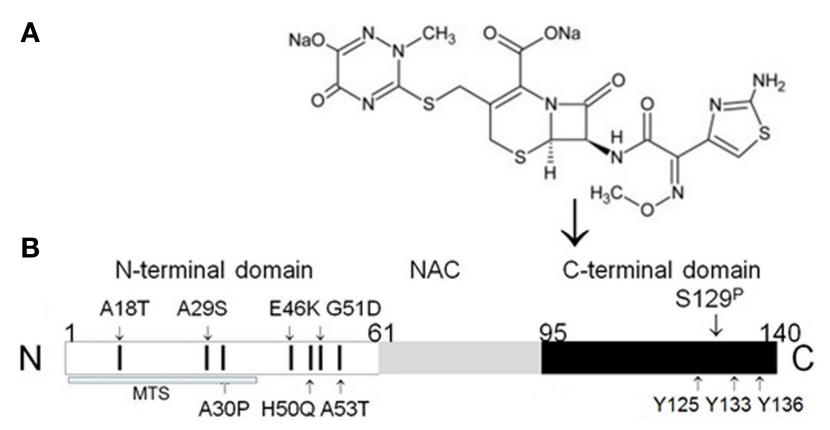

FIGURE 2 | Binding of $\beta$-lactam antibiotic ceftriaxone to $\alpha$-synuclein C-terminus. (A) Chemical structure of ceftriaxone. (B) Schematic organization of human $\alpha$-synuclein with localization of known missense mutations indicated by small arrows. $\mathrm{N}$-terminal domain contains all missense mutations, predisposing to $\alpha$-synuclein aggregation. These mutations include three well-characterized and carefully studied missense mutations: A53T (51), A30P (52), and E46K (53). The toxicity of these mutant forms of $\alpha$-synuclein may be due to their enhanced aggregation into oligomers and amyloid fibrils. Two recently identified mutations, which are not yet well investigated, H50Q (54) and G51D (55), may have an important effect on $\alpha$-synuclein properties, since they add new potential phosphorylation sites to the first N-terminal helix (56). Phosphorylation of Ser129 enhances aggregation of $\alpha$-synuclein (57). Y125, Y133, and Y136-tyrosine residues, which are a part of ceftriaxone-binding site (58). MTS, mitochondria-targeting sequence (42). Modified from Ghanizadeh and Berk (59). model of epilepsy (63) (see details in Section " $\alpha$-Synuclein Concentration Is Changed in Body Fluids of Epileptic Patients").

(c) $\beta$-Lactam antibiotics, such as ceftriaxone, known to reduce frequency of seizures bind to $\alpha$-synuclein and inhibit its aggregation (58).

We outline the physicochemical characteristics of $\alpha$-synuclein, which render this molecule capable of forming new ion channels.

\section{Structure and Functions of $\alpha$-Synuclein}

$\alpha$-Synuclein is an NUP of the synuclein family, which consists of three members, namely, $\alpha-, \beta-$, and $\gamma$-synuclein $(42,47)$. $\alpha$-Synuclein is a small protein (140 amino acids, $14 \mathrm{kDa}$ ) predominantly expressed in CNS neurons. $\alpha$-Synuclein amino acid sequence can be subdivided into three domains: N-terminal, amphipathic repeat region (residues 1-60), the so-called nonamyloid beta component domain (NAC-region, residues 61-95), and C-terminal acidic domain (residues 96-140) (Figure 2).

In physiological solutions, $\alpha$-synuclein is characterized by a lack of rigid, well-defined structure and exists predominantly in unfolded or intrinsically disordered form $(29,37,60)$. However, $\alpha$-synuclein possesses high conformational plasticity and is able to adopt a series of different conformations depending on the environmental conditions and binding partners (64). Importantly, formation of oligomers and aggregates is concentration dependent, increases at elevated $\alpha$-synuclein expression, underlies a toxic gain of function, and may lead to the development of pathology (65-67).

\section{$\alpha$-Synuclein Forms Annular Protofibrils Increasing Membrane Permeabilization}

Lashuel et al. (34) described the ability of $\alpha$-synuclein to form annular protofibrils, which might incorporate into membrane, form pores, and disturb membrane permeabilization leading to cell dysfunction and even cell death. This pathogenic-protofibril hypothesis was supported by biophysical studies of not only $\alpha$-synuclein but also other amyloidogenic proteins, e.g., A $\beta$ suggesting a putative common mechanism in Parkinson's and Alzheimer's diseases (34).

Protofibrillar $\alpha$-synuclein is able to induce vesicle permeabilization (37), while helical $\alpha$-synuclein forms highly conductive ion channels (35). Ding et al. (68) described production of annular $\alpha$-synuclein protofibrils when spherical protofibrils were incubated in solution or bound to brain-derived membranes.

\section{$\alpha$-Synuclein Concentration Is Changed in Body Fluids of Epileptic Patients}

Increased $\alpha$-synuclein concentration in serum, CSF, and specific brain regions has been described in epileptic patients as well as in an animal model of epilepsy. Li et al. (63) used the pilocarpine mouse model of temporal lobe epilepsy to screen the proteome and found a statistically significant increase in $\alpha$-synuclein expression in temporal lobe epilepsy. In another study, Rong et al. (62) found elevated concentration of total $\alpha$-synuclein in the CSF and serum of the epilepsy patients, as compared to the 
control. The authors concluded that $\alpha$-synuclein content in the serum and CSF may facilitate the identification of intractable epilepsy and serve as a valuable prognostic marker in the clinical assessment. Yang et al. (69) described aberrant expression of $\alpha$-synuclein in hippocampus from patients with mesial temporal lobe epilepsy. Thus, $\alpha$-synuclein is increased in body fluids of epileptic patients and can be used as an essential biological marker in epilepsy.

\section{$\beta$-Lactam Antibiotics with Antiseizure Activity Inhibit $\alpha$-Synuclein Aggregation}

$\beta$-Lactam antibiotics, e.g., ceftriaxone or cefixime, possess neuroprotective effect, exhibit excellent blood-brain barrier penetration, and suppress posttraumatic seizures. Ceftriaxone treatment ameliorates both seizure frequency and duration (70). Importantly, these antiseizure substances bind to $\alpha$-synuclein and affect its aggregation (58).

\section{Epigenetic Mechanisms Affecting $\alpha$-Synuclein Ability to Form Ion Channels}

Several mechanisms may affect $\alpha$-synuclein ability to form ion channels (Figure 3).

$\alpha$-Synuclein aggregation is a concentration-dependent process and therefore may be affected by the level of its expression. A number of mechanisms control the level of $\alpha$-synuclein expression, including transcriptional regulation by methylation/ demethylation of regulatory regions in $\alpha$-synuclein gene $(48,49)$ (mechanism \#1). Another mechanism controlling $\alpha$-synuclein expression is posttranscriptional regulation by microRNAs (43) (mechanism \#2). Finally, $\alpha$-synuclein posttranslational modification, e.g., phosphorylation predisposes it to conformational changes and aggregation $(44,57)$ (mechanism \#3) and may affect its pore formation capacity. In addition to its ability to form annular and ring-like structures (Figure 1) functioning as ion channels, $\alpha$-synuclein also interacts with intrinsic ion channels that build from other proteins and changes their properties (72). This feature of $\alpha$-synuclein may also change conductance through alteration of membrane permeability. Several mechanisms may affect the ability of $\alpha$-synuclein to form ion channels (Figure 3 ).

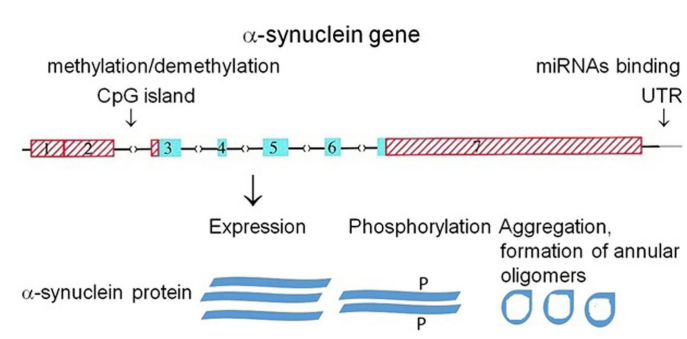

FIGURE 3 | Putative mechanisms affecting $\alpha$-synuclein ability to form ion channels. Organization of human $\alpha$-synuclein genes (71). Blue (coding) and red (untranslated) exons are shown in boxes; introns are shown as interrupted horizontal lines. Epigenetic mechanism: methylation of CpG islands and microRNA binding to $3^{\prime}$-UTR region of the gene regulate $\alpha$-synuclein expression on transcriptional and posttranscriptional level, respectively. Phosphorylation $(\mathrm{P})$ of $\alpha$-synuclein regulates its aggregation.

\section{Stefin B}

\section{Structure and Function of Stefin B}

Human stefin B is a member of cystatin superfamily consisting of single-chain protein, which is composed of 98 amino acid residues with a molecular mass of $11 \mathrm{kDa}(45)$. Stefin $\mathrm{B}$ is a neutral protein able to form a dimer stabilized by non-covalent forces. Similar to other members of the cystatin superfamily, stefin B is reversible and competitive inhibitor of cysteine proteases, particularly cathepsin L and cathepsin S. Stefin B is widely distributed among different cell types and tissues. Although it lacks an export signal sequence and is generally thought to function intracellularly, it has also been found in extracellular fluid (45). Stefin B plays a role in protecting cytosolic and cytoskeleton proteins against the cysteine proteases. Besides protease inactivation, stefin B binds other proteins forming a multiprotein complex, which might contribute to the disease in patients with progressive myoclonic epilepsies.

Eight mutations in the stefin B gene have been reported to associate with progressive myoclonic epilepsy of UnverrichtLundborg type (EPM1). Most of the disease alleles harbor an unstable expansion of at least 30 copies of a normally polymorphic 12-nucleotide, dodecamer repeat located in the promoter region of the stefin B gene. Three reported EPM1 mutations affect splice sites, two result in amino acid changes, and two predict truncated proteins due to a nonsense or frameshift mutation (45).

\section{Stefin B Forms Annular Protofibrils Increasing Membrane Permeabilization}

Although the function of stefin B in the pathogenesis of epilepsy is not completely understood, experiments in vitro show that two missense mutants G50E and Q71P aggregate to a much greater extent than the wild-type (WT) protein (50).

Calcein release results and electrophysiological measurements demonstrate that both WT stefin B and the Y31, but not G4R mutant isoform, are able to form pores in planar lipid bilayers, thereby increasing membrane permeabilization (41). Importantly, there is a clear distinction between oligomer size and toxicity. In the case of WT stefin B, the monomers, dimers, and tetramers of WT stefin B are not toxic, while higher species starting with hexamers and dodecamers acquire toxicity (73).

\section{Mechanisms Affecting the Formation of Ion Channels by Stefin B}

Mechanisms affecting stefin B expression and regulating its ability to form ion channels are similar to those described for $\alpha$-synuclein. Stefin B epigenetic mechanisms regulating its expression through DNA methylation are investigated in several diseases, including breast, pancreatic, brain, and lung cancer (46).

Patients with progressive epilepsy of the Unverricht-Lundborg type are characterized by myoclonic seizures and ataxia. The majority of such patients carry repeat expansions of a dodecamer with high GC content in the promoter region of the stefin B gene (74). Although the regulatory role of these dodecamer has not been investigated in detail, these GC stretches are the site of methylation/demethylation regulating the expression of the downstream gene. These findings suggest that DNA methylation-dependent 
epigenetic mechanisms may play a central role in the regulation of stefin B expression.

The knowledge of epigenetic mechanisms implicated in the development of epilepsy provides a conceptual and mechanistic framework for the future development of epigenetic therapies tailored to prevent epilepsy (antiepileptogenic) or its progression (disease modifying).

\section{DISCUSSION AND CONCLUSION}

Numerous causative mutations have been detected and characterized in familial cases of epilepsy, and the details about genetic mechanisms underlying this disease are accumulating. In contrast, the underlying mechanisms in a significant proportion of epilepsy patients remain unknown, thereby hampering treatment and drug development. We propose novel biochemical and epigenetic mechanisms, which provide alternative explanation for the development of idiopathic epilepsy. We consider here that certain NUPs may form new channels as a result of epigenetic modification(s) on transcriptional (methylation/demethylation of regulatory regions), posttranscriptional levels (microRNAdriven mechanism), or due to posttranslational modifications (phosphorylation, glycosylation of protein, etc.). We provide evidence that NUPs can bind to plasma membrane and form new ion channels that can alter intracellular ion homeostasis.

A role of NUPs in the formation of new channels, which may disrupt membrane conductance, disturb ion homeostasis, and ultimately lead to seizures, is based on several experimental findings:

(a) $\alpha$-Synuclein and other intrinsically unstructured proteins form annular protofibrils or pores, which incorporate into membrane and act as ion channels increasing membrane permeabilization $(34,35,37)$.

(b) Patients with $\alpha$-synuclein genetic defects have seizures (61).

(c) $\beta$-Lactam antibiotics, such as ceftriaxone, known to reduce frequency of seizures bind to $\alpha$-synuclein and inhibit its aggregation (58).

(d) $\alpha$-Synuclein concentration is elevated in the CSF and serum of epileptic patients (62) and in a mouse model of epilepsy (63).

Each of these findings individually may be considered only as indirect evidence. However, considering the molecular nature of $\alpha$-synuclein in the light of an increase in the frequency of seizures in parallel with its levels provides a strong argument in support of a potential role of $\alpha$-synuclein in epilepsy. Long duration of epileptogenesis provides sufficient time for manifestation of several possible epigenetic mechanisms, which may trigger the formation of novel ion channels. Alternatively, formation of novel ion channels and changes in membrane permeabilization may lead to epigenetic changes.

In fact, the proposed mechanism for ion channel formation may be widely distributed in the cell than currently imagined. In addition to plasma membrane, formation of ion channels may also be evident in intracellular organelles, e.g., membranes of mitochondria and lysosomes. Therefore, many details of epigenetic mechanisms remain to be determined in order to better understand the causes of sporadic epilepsy and their specific treatments.

Several alternative hypotheses have been proposed previously to explain the development of non-familial forms of epilepsy due to epigenetic mechanisms. Among them is an increased activity of DNA methylating enzymes leading to hypermethylation of DNA (75-79). Another proposed mechanism implicates histone modifications that involve the addition or removal of methyl or acetyl groups during epileptogenesis (21). Recently, Boison (16) proposed that adenosine and glycine may regulate epigenetic mechanisms of epileptogenesis. Other putative mechanisms of epileptogenesis are discussed in recent publications (80-83). Our hypothesis is different from those mentioned here. We believe that while acquired epilepsy is associated with ion channels, its etiology and pathophysiology are likely determined by the de novo formation of channels from NUPs.

The knowledge of new epigenetic mechanisms implicated in the development of epilepsy will provide a conceptual and mechanistic framework for future development of therapies tailored to prevent epilepsy (antiepileptogenic) or its progression (disease modifying).

\section{AUTHOR CONTRIBUTIONS}

AS put forward a hypothesis and wrote the manuscript; made analysis and interpretation of data; made a final approval of the version to be published; and agreed to be accountable for all aspects of the work. IS discussed hypothesis, wrote, and edited the manuscript; made substantial contributions to the conception of the work; made a final approval; and agreed to be accountable for all aspects of the work. MS discussed proposed hypothesis, wrote, and edited the manuscript; made analysis and interpretation of data; made a final approval of the version to be published; made a final approval; and agreed to be accountable for all aspects of the work. RS made contributions to the conception or design of the work; made a final approval of the version to be published; agreed to be accountable for all aspects of the work in ensuring questions related to the accuracy and integrity; and made interpretation of data. VS discussed proposed hypothesis, wrote, and edited the manuscript; made analysis and interpretation of data; made a final approval of the version to be published; made a final approval; and agreed to be accountable for all aspects of the work. RS made interpretation of data.

\section{FUNDING}

Some of the work by AS and IS cited in this manuscript was conducted at the Kansas City VA Medical Center, Kansas City, MO, USA, with support from VA Merit Review grants 1I01BX000361 and the Glaucoma Foundation grant QB42308. MS is supported, in part, by the Midwest Biomedical Research Foundation (MBRF), KC VA Medical Research Center, Kansas City, MO, USA, and as co-investigator for NIDDK 1RO1 DK107490. 


\section{REFERENCES}

1. Fisher RS, Acevedo C, Arzimanoglou A, Bogacz A, Cross JH, Elger CE, et al. ILAE official report: a practical clinical definition of epilepsy. Epilepsia (2014) 55(4):475-82. doi:10.1111/epi.12550

2. Epilepsy Across the Spectrum. Promoting health and understanding. In: England MJ, Liverman CT, Schultz AM, Strawbridge LM, editors. Institute of Medicine (US) Committee on the Public Health Dimensions of the Epilepsies. Washington, DC: National Academies Press (US) (2012). p. 19-49.

3. Striano P, Vari MS, Mazzocchetti C, Verrotti A, Zara F. Management of genetic epilepsies: from empirical treatment to precision medicine. Pharmacol Res (2016) 107:426-9. doi:10.1016/j.phrs.2016.04.006

4. Staley K. Molecular mechanisms of epilepsy. Nat Neurosci (2015) 18:367-72. doi:10.1038/nn.3947

5. Cunliffe VT, Baines RA, Giachello CN, Lin WH, Morgan A, Reuber M, et al. Epilepsy research methods update: understanding the causes of epileptic seizures and identifying new treatments using non-mammalian model organisms. Seizure (2015) 24:44-51. doi:10.1016/j.seizure.2014. 09.018

6. Hildebrand MS, Dahl HH, Damiano JA, Smith RJ, Scheffer IE, Berkovic SF. Recent advances in the molecular genetics of epilepsy. J Med Genet (2013) 50:271-9. doi:10.1136/jmedgenet-2012-101448

7. Mulley JC, Scheffer IE, Petrou S, Berkovic SF. Channelopathies as a genetic cause of epilepsy. Curr Opin Neurol (2003) 16:171-6. doi:10.1097/ 00019052-200304000-00009

8. Myers CT, Mefford HC. Advancing epilepsy genetics in the genomic era. Genome Med (2015) 7:91. doi:10.1186/s13073-015-0214-7

9. Nicita F, De Liso P, Danti FR, Papetti L, Ursitti F, Castronovo A, et al. The genetics of monogenic idiopathic epilepsies and epileptic encephalopathies. Seizure (2012) 21:3-11. doi:10.1016/j.seizure.2011.08.007

10. Poduri A, Lowenstein D. Epilepsy genetics - past, present and future. Curr Opin Genet Dev (2011) 21:325-32. doi:10.1016/j.gde.2011.01.005

11. Graves TD. Ion channels and epilepsy. QJM (2006) 99:201-17. doi:10.1093/ qjmed/hcl021

12. Steinlein OK. Genetic mechanisms that underlie epilepsy. Nat Rev Neurosci (2004) 5:400-8. doi:10.1038/nrn1388

13. Waszkielewicz AM, Gunia A, Szkaradek N, Słoczyńska K, Krupińska S, Marona H. Ion channels as drug targets in central nervous system disorders. Curr Med Chem (2013) 20(10):1241-85. doi:10.2174/09298673113 20100005

14. Löscher W, Brandt C. High seizure frequency prior to antiepileptic treatment is a predictor of pharmacoresistant epilepsy in a rat model of temporal lobe epilepsy. Epilepsia (2010) 51(1):89-97. doi:10.1111/j.1528-1167.2009. 02183.x

15. Löscher W, Brandt C. Prevention or modification of epileptogenesis after brain insults: experimental approaches and translational research. Pharmacol $\operatorname{Rev}$ (2010) 62(4):668-700. doi:10.1124/pr.110.003046

16. Boison D. The biochemistry and epigenetics of epilepsy: focus on adenosine and glycine. Front Mol Neurosci (2016) 13(9):26. doi:10.3389/fnmol.2016. 00026

17. Aranda S, Shi Y, Di Croce L. Chromatin and epigenetics at the forefront: finding clues among peaks. Mol Cell Biol (2016) 36(19):2432-9. doi:10.1128/ MCB.00328-16

18. Qureshi IA, Mehler MF. Epigenetic mechanisms underlying human epileptic disorders and the process of epileptogenesis. Neurobiol Dis (2010) 39(1):53-60. doi:10.1016/j.nbd.2010.02.005

19. Kobow K, Blümcke I. The emerging role of DNA methylation in epileptogenesis. Epilepsia (2012) 53(9):11-20. doi:10.1111/epi.12031

20. Lubin FD. Epileptogenesis: can the science of epigenetics give us answers? Epilepsy Curr (2012) 12(3):105-10. doi:10.5698/1535-7511-12.3.105

21. Henshall DC, Kobow K. Epigenetics and epilepsy. Cold Spring Harb Perspect Med (2015) 5:12. doi:10.1101/cshperspect.a022731

22. Gao WM, Chadha MS, Kline AE, Clark RS, Kochanek PM, Dixon CE, et al. Immunohistochemical analysis of histone $\mathrm{H} 3$ acetylation and methylation - evidence for altered epigenetic signaling following traumatic brain injury in immature rats. Brain Res (2006) 1070:31-4. doi:10.1016/j.brainres. 2005.11.038

23. Zhang ZY, Zhang Z, Fauser U, Schluesener HJ. Global hypomethylation defines a sub-population of reactive microglia/macrophages in experimental traumatic brain injury. Neurosci Lett (2007) 429(1):1-6. doi:10.1016/ j.neulet.2007.09.061

24. Lundberg J, Karimi MC, von Gertten C, Holmin S, Ekström TJ, Sandberg-Nordqvist AC. Traumatic brain injury induces relocalization of DNA-methyltransferase 1. Neurosci Lett (2009) 457:8-11. doi:10.1016/ j.neulet.2009.03.105

25. Born HA. Seizures in Alzheimer's disease. Neuroscience (2015) 286:251-63. doi:10.1016/j.neuroscience.2014.11.051

26. Costa C, Parnetti L, D’Amelio M, Tozzi A, Tantucci M, Romigi A, et al. Epilepsy, amyloid- $\beta$, and D1 dopamine receptors: a possible pathogenetic link? Neurobiol Aging (2016) 48:161-71. doi:10.1016/j.neurobiolaging. 2016.08.025

27. Sima X, Xu J, Li J, Zhong W, You C. Expression of $\beta$-amyloid precursor protein in refractory epilepsy. Mol Med Rep (2014) 9(4):1242-8. doi:10.3892/ mmr.2014.1977

28. Dyson HJ, Wright PE. Intrinsically unstructured proteins and their functions. Nat Rev Mol Cell Biol (2005) 6(3):197-208. doi:10.1038/nrm1589

29. Fink AL. Natively unfolded proteins. Curr Opin Struct Biol (2005) 15(1):35-41. doi:10.1016/j.sbi.2005.01.002

30. Ross CA, Poirier MA. Opinion: what is the role of protein aggregation in neurodegeneration? Nat Rev Mol Cell Biol (2005) 6(11):891-8. doi:10.1038/ nrm 1742

31. Salahuddin P, Fatima MT, Abdelhameed AS, Nusrat S, Khan RH. Structure of amyloid oligomers and their mechanisms of toxicities: targeting amyloid oligomers using novel therapeutic approaches. Eur JMed Chem (2016) 114:41-58. doi:10.1016/j.ejmech.2016.02.065

32. Soto C. Unfolding the role of protein misfolding in neurodegenerative diseases. Nat Rev Neurosci (2003) 4(1):49-60. doi:10.1038/nrn1007

33. Soto C. Protein misfolding in neurodegenerative diseases: the key pending questions. J Neurol Transl Neurosci (2013) 1:1010.

34. Lashuel HA, Hartley D, Petre BM, Walz T, Lansbury PT Jr. Neurodegenerative disease: amyloid pores from pathogenic mutations. Nature (2002) 418(6895):291. doi:10.1038/418291a

35. Zakharov SD, Hulleman JD, Dutseva EA, Antonenko YN, Rochet JC, Cramer WA. Helical alpha-synuclein forms highly conductive ion channels. Biochemistry (2007) 46(50):14369-79. doi:10.1021/bi701275p

36. Lashuel HA, Lansbury PT Jr. Are amyloid disease caused by protein aggregates that mimic bacterial pore-forming toxins. Q Rev Biophys (2006) 39:167-202. doi:10.1017/S0033583506004422

37. Volles MJ, Lee SJ, Rochet JC, Shtilerman MD, Ding TT, Kessler JC, et al. Vesicle permeabilization by protofibrillar alpha-synuclein: implications for the pathogenesis and treatment of Parkinson's disease. Biochemistry (2001) 40(26):7812-9. doi:10.1021/bi0102398

38. Butterfield SM, Lashuel HA. Amyloidogenic protein-membrane interactions: mechanistic insight from model systems. Angew Chem Int Ed Engl (2010) 49(33):5628-54. doi:10.1002/anie.200906670

39. Kagan BL, Thundimadathil J. Amyloid peptide pores and the beta sheet conformation. Adv Exp Med Biol (2010) 677:150-67. doi:10.1007/978-14419-6327-7_13

40. Butterfield SM, Lashuel HA. Amyloidogenic protein-membrane interactions: mechanistic insight from model systems. Angew. Chem. Int. Ed (2010) 49(33):5628-54. doi:10.1002/anie.200906670

41. Rabzelj S, Viero G, Gutiérrez-Aguirre I, Turk V, Dalla Serra M, Anderluh G, et al. Interaction with model membranes and pore formation by human stefin B: studying the native and prefibrillar states. FEBS J (2008) 275(10):2455-66. doi:10.1111/j.1742-4658.2008.06390

42. Surguchov A. Intracellular dynamics of synucleins: "here, there and everywhere". Int Rev Cell Mol Biol (2015) 320:103-69. doi:10.1016/bs.ircmb. 2015.07.007

43. Doxakis E. Post-transcriptional regulation of alpha-synuclein expression by mir-7 and mir-153. J Biol Chem (2010) 285(17):12726-34. doi:10.1074/jbc. M109.086827

44. Pronin AN, Morris AJ, Surguchov A, Benovic JL. Synucleins are a novel class of substrates for G protein-coupled receptor kinases. J Biol Chem (2000) 275(34):26515-22. doi:10.1074/jbc.M003542200

45. Jevnikar Z, Kos J. CSTB (cystain B (stefin B)). Atlas Genet Cytogenet Oncol Haematol (2009) 13(6):406-8. doi:10.4267/2042/44486

46. Rivenbark AG, Coleman WB. Epigenetic regulation of cystatins in cancer. Front Biosci (2009) 14:453-62. doi:10.2741/3254 
47. Surguchov A. Molecular and cellular biology of synucleins. Int Rev Cell Mol Biol (2008) 270:225-317. doi:10.1016/S1937-6448(08)01406-8

48. Jowaed A, Schmitt I, Kaut O, Wüllner U. Methylation regulates alphasynuclein expression and is decreased in Parkinson's disease patients' brains. J Neurosci (2010) 30(18):6355-9. doi:10.1523/JNEUROSCI.611909.2010

49. Matsumoto L, Takuma H, Tamaoka A, Kurisaki H, Date H, Tsuji S, et al. CpG demethylation enhances alpha-synuclein expression and affects the pathogenesis of Parkinson's disease. PLoS One (2010) 5(11):e15522. doi:10.1371/ journal.pone.0015522

50. Polajnar M,Zavašnik-Bergant T, Kopitar-Jerala N, Tušek-Žnidarič M,Zerovnik E. Gain in toxic function of stefin B EPM1 mutants aggregates: correlation between cell death, aggregate number/size and oxidative stress. Biochim Biophys Acta (2014) 1843(9):2089-99. doi:10.1016/j.bbamcr.2014.05.018

51. Polymeropoulos MH, Lavedan C, Leroy E, Ide SE, Dehejia A, Dutra A, et al. Mutation in the alpha-synuclein gene identified in families with Parkinson's disease. Science (1997) 276(5321):2045-7. doi:10.1126/science.276.5321.2045

52. Kruger R, Kuhn W, Muller T, Woitalla D, Graeber M, Kosel S, et al. Ala30Pro mutation in the gene encoding alpha-synuclein in Parkinson's disease. Nat Genet (1998) 18(2):106-8. doi:10.1038/ng0298-106

53. Zarranz JJ, Alegre J, Gomez-Esteban JC, Lezcano E, Ros R, Ampuero I, et al. The new mutation, E46K, of alpha-synuclein causes Parkinson and Lewy body dementia. Ann Neurol (2004) 55(2):164-73. doi:10.1002/ana.10795

54. Appel-Cresswell S, Vilarino-Guell C, Encarnacion M, Sherman H, Yu I, Shah B, et al. Alpha-synuclein p.H50Q, a novel pathogenic mutation for Parkinson's disease. Mov Disord (2013) 28:811-3. doi:10.1002/mds.25421

55. Lesage S, Anheim M, Letournel F, Bousset L, Honoré A, Rozas N, et al. French Parkinson's Disease Genetics Study Group. G51D a-synuclein mutation causes a novel parkinsonian pyramidal syndrome. Ann Neurol (2013) 73(4):459-71. doi:10.1002/ana.23894

56. Hoffman-Zacharska D, Koziorowski D, Ross OA, Milewski M, Poznanski J, Jurek M, et al. Novel A18T and pA29S substitutions in a-synuclein may be associated with sporadic Parkinson's disease. Parkinsonism Relat Disord (2013) 19(11):1057-60. doi:10.1016/j.parkreldis.2013.07.011

57. Fujiwara H, Hasegawa M, Dohmae N, Kawashima A, Masliah E, Goldberg MS, et al. alpha-Synuclein is phosphorylated in synucleinopathy lesions. Nat Cell Biol (2002) 4(2):160-4. doi:10.1038/ncb748

58. Ruzza P, Siligardi G, Hussain R, Marchiani A, Islami M, Bubacco L, et al. Ceftriaxone blocks the polymerization of $\alpha$-synuclein and exerts neuroprotective effects in vitro. ACS Chem Neurosci (2014) 5(1):30-8. doi:10.1021/ $\mathrm{cn} 400149 \mathrm{k}$

59. Ghanizadeh A, Berk M. Beta-lactam antibiotics as a possible novel therapy for managing epilepsy and autism. Iran J. Child. Neurol (2015) 9(1):99-102.

60. Weinreb PH, Zhen W, Poon AW, Conway KA, Lansbury PT Jr. NACP, a protein implicated in Alzheimer's disease and learning, is natively unfolded. Biochemistry (1996) 35:13709-15. doi:10.1021/bi961799n

61. Puschmann A, Wszolek ZK, Farrer M, Gustafson L, Widner H, Nilsson C. Alpha-synuclein multiplications with Parkinsonism, dementia or progressive myoclonus? Parkinsonism Relat Disord (2009) 15(5):390-2. doi:10.1016/ j.parkreldis.2008.08.002

62. Rong H, Jin L, Wei W, Wang X, Xi Z. Alpha-synuclein is a potential biomarker in the serum and CSF of patients with intractable epilepsy. Seizure (2015) 27:6-9. doi:10.1016/j.seizure.2015.02.007

63. Li A, Choi YS, Dziema H, Cao R, Cho HY, Jung YJ, et al. Proteomic profiling of the epileptic dentate gyrus. Brain Pathol (2010) 20(6):1077-89. doi:10.1111/j.1750-3639.2010.00414.x

64. Uversky VN. A protein-chameleon: conformational plasticity of alphasynuclein, a disordered protein involved in neurodegenerative disorders. JBiomol Struct Dyn (2003) 21(2):211-34. doi:10.1080/07391102.2003. 10506918

65. MacCormack A, Di Monte DA. Enhanced alpha-synuclein expression in human neurodegenerative diseases: pathogenetic and therapeutic implications. Curr Protein Pept Sci (2009) 10(5):476-82. doi:10.2174/ 138920309789351912

66. Oliveras-Salvá M, Van der Perren A, Casadei N, Stroobants S, Nuber S, D'Hooge R, et al. rAAV2/7 vector-mediated overexpression of alphasynuclein in mouse substantia nigra induces protein aggregation and progressive dose-dependent neurodegeneration. Mol Neurodegener (2013) 25(8):44. doi:10.1186/1750-1326-8-44
67. Munishkina LA, Cooper EM, Uversky VN, Fink AL. The effect of macromolecular crowding on protein aggregation and amyloid fibril formation. J Mol Recognit (2004) 17(5):456-64. doi:10.1002/jmr.699

68. Ding TT, Lee SJ, Rochet JC, Lansbury PT. Annular alpha-synuclein protofibrils are produced when spherical protofibrils are incubated in solution or bound to brain-derived membranes. Biochemistry (2002) 41(32):10209-17. doi:10.1021/bi020139h

69. Yang JW, Czech T, Felizardo M, Baumgartner C, Lubec G. Aberrant expression of cytoskeleton proteins in hippocampus from patients with mesial temporal lobe epilepsy. Amino Acid (2006) 30(4):477-93. doi:10.1007/ s00726-005-0281-y

70. Goodrich GS, Kabakov AY, Hameed MQ, Dhamne SC, Rosenberg PA, Rotenberg A. Ceftriaxone treatment after traumatic brain injury restores expression of the glutamate transporter, GLT-1, reduces regional gliosis, and reduces post-traumatic seizures in the rat. J Neurotrauma (2013) 30(16):143441. doi:10.1089/neu.2012.2712

71. Lavedan C. The synuclein family. Genome Res (1998) 8(9):871-80.

72. Rostovtseva TK, Gurnev PA, Protchenko O, Hoogerheide DP, Yap TL, Philpott CC, et al. $\alpha$-Synuclein shows high affinity interaction with voltage-dependent anion channel, suggesting mechanisms of mitochondrial regulation and toxicity in Parkinson disease. J Biol Chem (2015) 290(30):18467-77. doi:10.1074/ jbc.M115.641746

73. Anderluh G, Zerovnik E. Pore formation by human stefin B in its native and oligomeric states and the consequent amyloid induced toxicity. Front Mol Neurosci (2012) 2(5):85. doi:10.3389/fnmol.2012.00085

74. Horiuchi H, Osawa M, Furutani R, Morita M, Tian W, Awatsu Y, et al. Polymerase chain reaction-based analysis using deaminated DNA of dodecamer expansions in CSTB, associated with Unverricht-Lundborg myoclonus epilepsy. Genet Test (2005) 9(4):328-33. doi:10.1089/gte.2005.9.328

75. Kobow K, Jeske I, Hildebrandt M, Hauke J, Hahnen E, Buslei R, et al. Increased reelin promoter methylation is associated with granule cell dispersion in human temporal lobe epilepsy. J Neuropathol Exp Neurol (2009) 68:356-64. doi:10.1097/NEN.0b013e31819ba737

76. Kobow K, Kaspi A, Harikrishnan KN, Kiese K, Ziemann M, Khurana I, et al. Deep sequencing reveals increased DNA methylation in chronic rat epilepsy. Acta Neuropathol (2013) 126:741-56. doi:10.1007/s00401-013-1168-8

77. Zhu Q, Wang L, Zhang Y, Zhao FH, Luo J, Xiao Z, et al. Increased expression of DNA methyltransferase 1 and $3 \mathrm{a}$ in human temporal lobe epilepsy. J Mol Neurosci (2012) 46:420-6. doi:10.1007/s12031-011-9602-7

78. Williams-Karnesky RL, Sandau US, Lusardi TA, Lytle NK, Farrell JM, Pritchard EM, et al. Epigenetic changes induced by adenosine augmentation therapy prevent epileptogenesis. J Clin Invest (2013) 123:3552-63. doi:10.1172/JCI65636

79. Miller-Delaney SF, Bryan K, Das S, McKiernan RC, Bray IM, Reynolds JP, et al. Differential DNA methylation profiles of coding and non-coding genes define hippocampal sclerosis in human temporal lobe epilepsy. Brain (2015) 138:616-31. doi:10.1093/brain/awu373

80. Hirose S, Okada M, Yamakawa K, Sugawara T, Fukuma G, Ito M, et al. Genetic abnormalities underlying familial epilepsy syndromes. Brain Dev (2002) 24(4):211-22. doi:10.1016/S0387-7604(02)00056-6

81. Meldrum B. Status epilepticus: the past and the future. Epilepsia (2007) 48(8):33-4. doi:10.1111/j.1528-1167.2007.01343.x

82. Meldrum BS, Rogawski MA. Molecular targets for antiepileptic drug development. Neurotherapeutics (2007) 4(1):18-61. doi:10.1016/j.nurt.2006.11.010

83. Pandolfo M. Genetics of epilepsy. Semin Neurol (2011) 31(5):506-18. doi:10.1055/s-0031-1299789

Disclaimer: The views expressed in this article are those of the authors and do not necessarily reflect the position or policy of the Department of Veterans Affairs or the United States Government.

Conflict of Interest Statement: The authors do not have any conflict of interest to declare regarding the contents of the article.

Copyright $\odot 2017$ Surguchov, Surgucheva, Sharma, Sharma and Singh. This is an open-access article distributed under the terms of the Creative Commons Attribution License (CC BY). The use, distribution or reproduction in other forums is permitted, provided the original author(s) or licensor are credited and that the original publication in this journal is cited, in accordance with accepted academic practice. No use, distribution or reproduction is permitted which does not comply with these terms. 